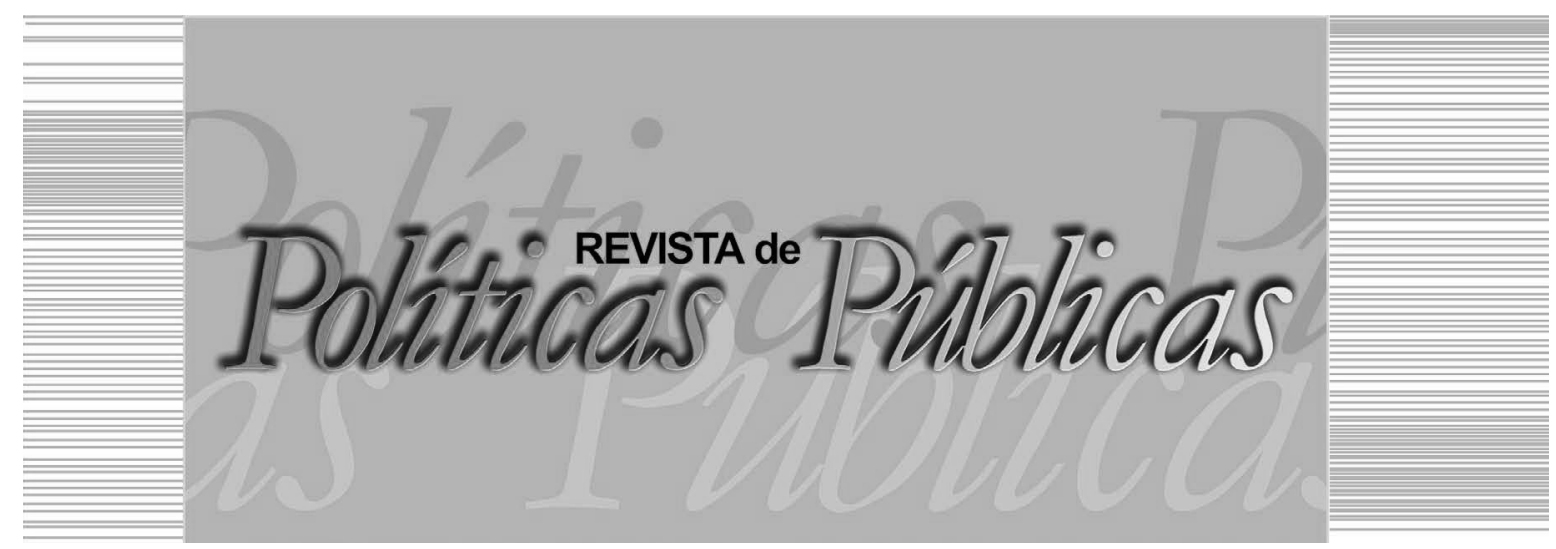

\title{
TRABALHADOR CANAVIEIRO NO BRASIL: estudo da legislação sobre contratação e condições de trabalho
}

\author{
Carolina Giraldo \\ Camila Marques $^{2}$
}

\section{Resumo}

Este trabalho analisou as leis que regem as relações dos trabalhadores canavieiros, com o intuito de refletir sobre o efeito dessas leis na melhora de suas condições de trabalho. A análise constituiu-se na metodologia de revisão bibliográfica, focando, especialmente, na Constituição Federal, tratados internacionais e legislações infraconstitucionais. $\mathrm{O}$ estudo mostrou que embora o crescimento econômico tenha ajudado na geração de novos empregos nesse setor, as condições de trabalho têm sido um grande problema, gerando efeitos na saúde dos cortadores, principalmente pela força de trabalho e a longa jornada que fazem com objetivo de cumprir a produção diária. O principal desencadeante dessa situação é a forma de pagamento que, em lugar de ser um salário fixo, é feito pela produtividade, $\mathrm{O}$ estudo concluiu, ainda, que existem legislações pertinentes que abordam esses problemas, porém o descumprimento dessas leis é frequente, o que impossibilita a melhoria das condições dos cortadores de cana. Palavras-chave: Legislação, cortadores de cana, setor sucroalcooleiro.

\footnotetext{
Biólogo, Meste em Ciências Ambientais pela Universidade Federal de São Carlos (UFSCar), Estudante de Pós-graduação no Programa de Ciências Ambientais UFSCar. E-mail: k-ritogiraldo@hotmail.com

2 Advogada, Meste em Ciências Ambientais, Estudante de Pós-graduação no Programa de Ciências Ambientais da UFSCar. E-mail: rcamillamarques@hotmail.com / Universidade Federal de São Carlos - UFSCar: Campus São Carlos - Rod. Washington Luís, km 235 - SP-310 - São Carlos. CEP 13565-905
} 
SUGARCANE WORKER IN BRAZIL: study of legislation on hiring and working conditions

\begin{abstract}
This study analyzed the laws governing the relations of sugarcane workers, with the purpose of reflecting on the effect of these laws on the improvement of their working conditions. The analysis consisted in the methodology of bibliographical review, focusing especially in the Federal Constitution, international deals and infraconstitutional legislations. The study showed that although economic growth has helped to generate new jobs in this sector, working conditions have been a big problem, generating effects on the health of the cutters, mainly by the work force and the long journey that they make with objective to meet daily production. The main trigger of this situation is the form of payment that instead of being a fixed salary, is done by productivity, and it was concluded that there are pertinent legislation that addresses these problems, however the noncompliance with these laws is frequent, which makes it impossible to improve the conditions of cane cutters.
\end{abstract}

Key words: Legislation, sugarcane cutters, sugar and alcohol industry.

\title{
1 INTRODUÇÃO
}

Este artigo pretende analisar algumas das leis trabalhistas que regem o setor canavieiro em relação á contratação e às condições de trabalho dos cortadores de cana no Brasil, tendo em conta que conforme estudos realizados anteriormente, a precariedade dos trabalhadores do setor tem sido constante ao longo do tempo.

É importante ressaltar que a indústria de cana de açúcar no Brasil tem sido de muita importância para o desenvolvimento econômico do país, não somente para a produção de recursos energéticos de uso alimentar humano e animal, mas também para suprir o aumento na demanda de combustíveis renováveis por causa da crise do petróleo. (PIRES; FERREIRA, 2008).

Embora o crescimento na indústria canavieira tenha causado impactos positivos no que diz respeito à geração de quase um milhão de empregos formais nos setores cana de açúcar e álcool, existe uma grande preocupação em relação às condições de trabalho dos cortadores de cana sobre os pagamentos por produtividade, uso da terceirização na contratação dos cortadores e migração de trabalhadores de outros estados. (MORAES, 2007). 
TRABALHADOR CANAVIEIRO NO BRASIL: estudo da legislação sobre contratação e condições de trabalho

A mecanização da coleta foi uma medida importante para a eliminação parcial da situação precária dos trabalhadores no setor canavieiro, do mesmo modo como para a redução de custos e da pressão ambiental que estava gerando a queima da cana para facilitar a coleta manual. (PAES, 2007). Porém, a adoção desta prática varia bastante entre as diferentes regiões produtoras do estado de São Paulo por fatores como a declividade das terras, já que somente nas terras planas se facilita o uso desse mecanismo, a predominância de grandes produtores que justificam a compra de uma maquinaria colhedora e o movimento sindical que tem maior grado de organização. (MORAES, 2007).

Os dados foram coletados por meio de revisão bibliográfica em acervos científicos e revistas especializadas sobre estudos que falassem das condições laborais dos trabalhadores do setor canavieiro, mais especificamente dos cortadores de cana de açúcar e os problemas em relação às exigências de trabalho.

Por outro lado, foi feita uma análise dos tratados internacionais, legislação constitucional e infraconstitucional e contratos coletivos de trabalho correspondentes aos trabalhadores do setor canavieiro para posteriormente discutir se as leis existentes são suficientes para garantir os direitos dos cortadores e melhorar as condições de trabalho.

\section{CONTEXTO}

Historicamente, acredita-se que a cana-de-açúcar tenha seu centro de origem no Sudeste Asiático, aparecendo primeiramente nas ilhas do Arquipélago da Polinésia e documentada pelas primeiras vezes nas escrituras mitológicas dos hindus e até mesmo nas Sagradas Escrituras. "Até meados do século XVIII foi considerada como remédio e artigo de luxo, as caravelas ao iniciarem suas viagens levaram mudas para servirem de suprimento para suas expedições.” (ARIED JUNIOR, 2013, p. 6).

No Brasil, a indústria canavieira sempre teve grande importância no desenvolvimento econômico, sendo que inicialmente a introdução da cana-de- açúcar no país foi feita no século XVI exclusivamente para produção de açúcar para exportação, sendo que durante o Brasil Império, o país dependeu principalmente dessa economia. Em meados do século XVII o país tornou-se o maior produtor de cana-de-açúcar, o que gerou, consequentemente, a perda de 
quase $93 \%$ da cobertura original da Mata Atlântica (RODRIGUES; ORTIZ, 2006), utilizando o trabalho escravo como base do setor.

De acordo com Specian e Figueiredo (2010) um fator relevante no contexto da atividade canavieira em qualquer momento de sua história é a relação de trabalho existente no setor, pois ainda nos dias de hoje é possível encontrar indícios de trabalho escravo em usinas e destilarias em todos os estados do Brasil.

Utilizando-se desta mão de obra, a cana-de-açúcar tem sido cultivada para a produção de recursos energéticos de uso alimentar humano como, por exemplo, açúcar, melado e garapa, e de uso animal como volumoso para ração e matéria fresca. Mais recentemente o aumento dos cultivos tem sido gerado pela produção de álcool combustível a causa da crise do petróleo, pelo qual se procura fazer uso de combustíveis renováveis. (PIRES; FERREIRA, 2008).

No ano de 1979, quando o governo federal iniciou o programa Pró-Álcool como estímulo para a produção de álcool como combustível, uma grande quantidade de empregos foi ofertada no setor sucroalcooleiro, porém a qualidade do trabalho gerado estava marcada pela sazonalidade e precariedade dos direitos trabalhistas, onde emergiu a força de trabalho infantil, fraude nos sistemas de medida e remuneração do trabalho, deslocamentos de pessoas em busca de emprego, denúncias de trabalho escravo, entre outros. (GONÇALVES, 2005).

Ainda no final da década de 1990 os problemas com os trabalhadores nos cultivos de cana-de-açúcar continuavam, agora também em relação ao desemprego gerado pela mecanização da colheita já que as prefeituras não davam conta para atender a demanda de assistência social para essas famílias. (GONÇALVES, 2002; ALVES, 2008).

Por outro lado, os poucos trabalhadores que conseguiam empregos tinham que trabalhar em condições ainda piores, já que a atividade de corte de cana era paga pela produtividade, que era calculada fazendo pesagem dos metros de cana colhida e, posteriormente, convertidos em toneladas. (ALVES, 2006).

Conforme Rodrigues e Ortiz (2006), mais recentemente, a opção de uso de mão de obra migrante foi uma estratégia das empresas para baixar os custos de produção do setor sucroalcooleiro, já que a admissão era feita sem registro ou por meio de contratantes 
ilegais, e os trabalhadores alojados em casas dentro dos canaviais, longe das famílias, sem acesso às redes locais de proteção como os sindicatos, e à mercê da vontade dos empregadores.

\section{LEGISLACÕESS TRABALHISTAS E O SETOR CANAVIEIRO}

O modelo de monocultura utilizado para exportação da cana-de-açúcar gerou, ao longo da história, conflitos sociais com povos indígenas, trabalhadores e pequenos agricultores, posto que não somente se contrapõe às políticas que garantem soberania alimentar por ter produzido redução nos cultivos de outros tipos de alimentos (RODRIGUES; ORTIZ, 2006), mas também pelo uso de mão de obra nas usinas de atividade sucroalcooleira para realizar trabalho em condições precárias e desumanas. (BIODIVERSIDAD EN AMÉRICA LATINA Y EL CARIBE, 2006).

Nessa perspectiva, um dos principais problemas sociais em torno à atividade sucroalcooleira está relacionado à carga de trabalho físico, realizado pelos trabalhadores canavieiros, com o fim de aumentar a produtividade, dado que são obrigados a colher até quinze toneladas de cana por dia. (PARANAIBA; FERREIRA, 2013).

Sendo assim, quando se fala em qualidade de vida no que diz respeito ao setor, é essencial tratar da legislação trabalhista do trabalhador canavieiro, tendo em vista a evolução histórica da colheita da cana-de-açúcar, que, como é sabido, iniciou-se no Brasil por meio da mão de obra de pessoas escravizadas, e até os dias de hoje é possível encontrar pessoas trabalhando em condições análogas às do período da escravidão.

Conforme ensinam Barros e outros (2014), o setor sucroalcooleiro hoje atravessa uma nova fase no Brasil, e a mecanização vem substituindo o trabalho humano; a diminuição do número de cortadores também foi acompanhada por uma melhora das condições de trabalho daqueles que ainda se dedicam à colheita manual.

Porém, isso não significa que a exploração nos canaviais (incluindo casos de trabalho escravo) seja página virada na história do Brasil. Ainda existem milhares de cortadores manuais de cana, muitos submetidos a sérias violações trabalhistas. Há registros de operadores de máquinas colhedoras que trabalharam em turnos de até 27 
horas seguidas. Sinal de que muito precisa ser feito para mudar as condições de trabalho nas lavouras de cana. (BARROS et. al., 2014)

Com o viés de combater qualquer trabalho escravo ou análogo à escravidão, a Organização Internacional do Trabalho (OIT, 1998), por meio de sua Declaração sobre os Princípios e Direitos Fundamentais do Trabalho, estabelece que todos os seus membros possuem o compromisso de respeitar, promover e tornar realidade, de boa fé, os princípios relativos aos direitos fundamentais que são objeto dessas convenções, dentre eles: a eliminação de todas as formas de trabalho forçado ou obrigatório.

Por outro lado, conforme a Consolidação das Leis do Trabalho (CLT), no Brasil, existem cinco modalidades de relação de emprego, quais sejam: Contrato de trabalho por prazo indeterminado; Contrato de trabalho por prazo determinado; Contrato de trabalho temporário. Dessa forma, os trabalhadores canavieiros podem ser contratados tanto por período indeterminado, cujo prazo existe para início da prestação de serviço, mas não existe para o fim, quanto por período determinado que, de acordo com o art. $443^{\circ}$ da CLT, será de até dois anos de duração.

Há que se falar, que estes trabalhadores são trabalhadores rurais regidos por legislação própria, qual seja a Lei $\mathrm{n}^{\circ} 5.889$, de 8 de junho de 1973 que estatui normas reguladoras do trabalho rural, alterada pela Lei $\mathrm{n}^{\mathrm{o}} 11.718$, de 20 de junho de 2008 , que determina que apenas o produtor rural, pessoa física, proprietário ou não, que explore diretamente atividade agroeconômica, pode contratar o trabalhador por prazo reduzido de até dois meses, e, dentro do período de um ano, converte-se em contrato de trabalho por prazo indeterminado. (BRASIL, 1973, 2008).

A importância dessa modalidade de contratação se dá para o empregador, porque no setor sucroalcooleiro a colheita da cana-de-açúcar se faz por safras em determinados períodos do ano, e, para o empregado, há a possibilidade de ser incluído como trabalhador na Previdência Social.

Conforme o art. $35^{\circ}$ da Lei ${ }^{\circ} 4.870$, de 1 dezembro de 1965 , os trabalhadores da agroindústria canavieira terão direito a programas de assistência social os quais têm por objetivo: higiene e saúde, por meio de assistência médica, hospitalar e farmacêutica, bem como à maternidade e à infância, complementando a assistência prestada 
pela usinas e fornecedores de cana;complementação dos programas de educação profissional e de tipo médio gratuitas;estímulo e financiamento a cooperativas de consumo;financiamento de culturas de subsistência, nas áreas de terras utilizadas pelos trabalhadores rurais e promoção e estímulo de programas educativos, culturais e de recreação.

As relações de prestação de serviços dos trabalhadores canavieiros resultam de uma Convenção Coletiva de Trabalho; dessa forma, a CLT estabelece que convenções são um acordo de caráter normativo pelo qual dois ou mais sindicatos representativos de categorias econômicas e profissionais estipulam condições de trabalho aplicáveis, no âmbito das respectivas representações, às relações individuais de trabalho.

Nesse sentido, podem existir diversas convenções para o mesmo setor, e, dependendo da vontade das partes, (estas convenções) são aplicadas ao contrato particular de trabalho, e podem se sobrepor às leis trabalhistas. As convenções do setor são, na maior parte das vezes, um acordo entre representantes dos trabalhadores na agricultura e representantes dos sindicatos dos trabalhadores rurais, como ocorre com a Convenção Coletiva de Trabalho do Setor Sucroalcooleiro Goiano (FEDERAÇÃO DOS TRABALHADORES NA AGRICULTURA DO ESTADO DE GOIÁS, 2015) ou por representantes de sindicatos dos cultivadores de cana, representantes dos sindicatos dos produtores de açúcar e álcool e representantes dos sindicatos de trabalhadores da agricultura, como ocorre na Convenção Coletiva de Trabalho do Estado do Pernambuco (FEDERAÇÃO DOS TRABALHADORES NA AGRICULTURA DO ESTADO DO PERNAMBUCO, 2014).

Segundo a CLT, as convenções pretendem garantir um acordo entre as partes que permita um equilíbrio nas relações trabalhistas, porém nem sempre foi assim, pois os conflitos por direitos trabalhistas dos trabalhadores canavieiros têm sido recorrentes na história do Brasil, uma vez que, ainda nos dias atuais, mesmo com as convenções, veem seus direitos frequentemente desrespeitados.

A título de exemplo, a Convenção Coletiva de Trabalho do Setor Sucroalcooleiro Goiano (FEDERAÇÃO DOS TRABALHADORES NA AGRICULTURA DO ESTADO DE GOIÁS, 2015), além de um piso salarial, para trabalhadores na lavoura canavieira, estabelecido na sua cláusula terceira equivalente a R\$ 910,00 (no- 
vecentos e dez reais) mensais a partir de 20 de março de 15 , respeitando-se as práticas locais, também estabelece que os trabalhadores possam ser remunerados por metro de cana cortada, ficando fixado o valor da tonelada da cana cortada, que está disponível na referida convenção, conforme demonstra Tabela 1 a seguir:

Tabela 1 - Tabela do valor da tonelagem por hectare por preço por meio de metro linear

\begin{tabular}{c|c|c|c}
\hline Tipo & Tonelagem por hectare & Preço por meio metro linear & \\
\hline & & Em pé & Caída \\
\hline 1 & $110-129$ & 0,4376 & 0,5468 \\
\hline 2 & $100-109$ & 0,3828 & 0,4791 \\
\hline 3 & $90-99$ & 0,3457 & 0,4324 \\
\hline 4 & $70-89$ & 0,2918 & 0,3645 \\
\hline 5 & $50-69$ & 0,2185 & 0,2734 \\
\hline 6 & Até 49 & 0,1452 & 0,1821 \\
\hline
\end{tabular}

Fonte: FEDERAÇÃO DOS TRABALHADORES NA AGRICULTURA DO ESTADO DE GOIÁS. Convenção de Trabalho do Setor Sucroalcooleiro Goiano 2015/2016. Gioânia: Gráfica Liberdade, 2015. Disponível em:<http://www.fetaeg.org.br/NetManager/documentos/convencao_coletiva_do_trabalho_do_setor_sucroalcooleiro_goiano.pdf> Acesso em:26 nov. 2016.

Como demonstrado na tabela, para que um trabalhador saiba qual a sua remuneração pelo corte da cana, ele precisa converter o valor da tonelada cortada por metro cortado, já que apenas o valor da tonelada cortada está previamente fixado, ou seja, quanto mais cana um trabalhador corta, mais dinheiro ele recebe; esse sistema de remuneração é entendido como um estímulo à degradação da saúde dos trabalhadores. Em busca de um salário mais alto, eles fazem um esforço tão grande que pode gerar paradas cardíacas e até levá-los à morte. Só entre 2004 e 2009, 23 cortadores faleceram em decorrência do esforço excessivo nas lavouras. (BARROS et al., 2014).

Com o intuito de garantir as necessidades básicas do trabalhador, a Constituição Federal (CF) de 1988 estabelece que são direitos dos trabalhadores urbanos e rurais, o salário mínimo, fixado em Lei, nacionalmente unificado, "[...] capaz de atender a suas necessidades vitais básicas e às de sua família, com moradia, alimentação, educação, saúde, lazer, vestuário, higiene, transporte e previdência social, com reajustes periódicos que lhe preservem o poder aquisitivo, sendo vedada sua vinculação para qualquer fim”. (BRASIL, 1988).

Ocorre, todavia, que muitas CLT estabelecem um piso salarial, inferior ao salário mínimo vigente em território nacional, como 
TRABALHADOR CANAVIEIRO NO BRASIL: estudo da legislação sobre contratação e condições de trabalho

é possível exemplificar que em maio de 2008, o salário mínimo foi fixado em $\mathrm{R} \$ 415,00$ (quatrocentos e quinze reais), valor inferior ao mínimo estabelecido para o piso salarial dos cortadores de cana, que é de $\mathrm{R} \$ 526,00$ (quinhentos e vinte e seis reais); apesar disso, ele ainda não consegue suprir as necessidades básicas do trabalhador $\mathrm{e}$ de sua família, pois as leis trabalhistas, acordos e convenções coletivas de trabalho são comumente descumpridas, causando perdas significativas ao trabalhador. (CAMARGO, 2009)

Recentemente houve alterações da CLT, por meio da Lei $\mathrm{n}^{\circ}$ 13.467, publicada em 14 de julho de 2017, que mudou diversos dispositivos, todavia nenhum deles afeta diretamente as condições do trabalhador canavieiro, visto que eles já são na maioria das vezes contratados por período de produção ou acordo coletivo de trabalho. (BRASIL, 2017).

A CF, em seu art. $225^{\circ}$, também busca o uso racional dos recursos naturais quando estabelece que: "[...] todos têm direito ao meio ambiente ecologicamente equilibrado, bem de uso comum do povo e essencial à sadia qualidade de vida, se impondo ao Poder Público e à coletividade o dever de defendê-lo e preservá- lo para as presentes e futuras gerações". (BRASIL, 1988).

Essa busca de acordo com o então Ministro Celso de Mello, sobre o meio ambiente ecologicamente equilibrado, trata-se do mais importante princípio do direito ambiental, que se refere a um direito fundamental que está relacionado à sadia qualidade de vida, "[...] constituindo prerrogativa jurídica de titularidade coletiva, refletindo, dentro do processo de afirmação dos direitos humanos, a expressão significativa de um poder atribuído, não ao indivíduo identificado em sua singularidade, mas, num sentido verdadeiramente mais abrangente, à própria coletividade social.” (BRASIL, 1995).

Dessa forma, a qualidade de vida do trabalhador canavieiro é essencial para o desenvolvimento da economia, bem como para a coletividade social, refletindo na sustentabilidade de uma economia em desenvolvimento, seja ela local, regional ou internacional. (CAMARGO, 2009). 


\section{TRABALHO ESCRAVO E LEGISLAÇÃO VIGENTE}

A Convenção $\mathrm{n}^{\circ} 29$, da OIT, entende por trabalhos forçados "Todo trabalho ou serviço exigido de uma pessoa sob a ameaça de sanção e para o qual não se tenha oferecido espontaneamente." (ORGANIZAÇÃO INTERNACIONAL DO TRABALHO, 1930); na mesma linha, a Declaração da OIT sobre os Princípios e Direitos Fundamentais no Trabalho determina que todos os membros da OIT têm o compromisso de respeitar, promover e tornar realidade, de boa fé e em conformidade com a Constituição da Organização, os princípios relativos aos direitos fundamentais que são objeto dessas convenções, dentre os quais a eliminação de todas as formas de trabalho forçado ou obrigatório. (ORGANIZAÇÃO INTERNACIONAL DO TRABALHO, 1998).

Segundo estudo realizado pela OIT (2010), As Boas Práticas da Inspeção do Trabalho no Brasil: a erradicação do Trabalho Análogo ao de Escravo, no ano de 1995 o Governo Brasileiro reconheceu oficialmente a existência de trabalho em condição análoga à de escravo no país e começou a tomar medidas para erradicá-lo. Em relação à inspeção do trabalho, isso se concretizou com a criação, no mesmo ano, do Grupo Especial de Fiscalização Móvel (GEFM).

Posteriormente, nos anos de 2002 e 2003 respectivamente, o país iniciou a execução do Projeto de cooperação técnica Combate ao Trabalho Forçado no Brasil, da OIT e lançou o Primeiro Plano Nacional para a Erradicação do Trabalho Escravo, elaborado pela Comissão Especial do Conselho de Defesa dos Direitos da Pessoa Humana (CDDPH).

Já no ano de 2003 houve a criação da Comissão Nacional de Erradicação do Trabalho Escravo (CONATRAE), do acordo de Solução Amistosa entre o Estado Brasileiro, representado pela Secretaria Especial de Direitos Humanos da Presidência da República, e as peticionárias, representadas pelo Centro pela Justiça e o Direito Internacional, CEJIL-Brasil e a Comissão Pastoral da Terra, havendo uma evolução histórica de interesse ao combate à mão de obra escrava, como demonstra a Figura 1 a seguir. 
TRABALHADOR CANAVIEIRO NO BRASIL: estudo da legislação sobre contratação e condições de trabalho

Figura 1 - Evolução histórica dos instrumentos de fiscalização de trabalho escravo criados em parceria com a OIT

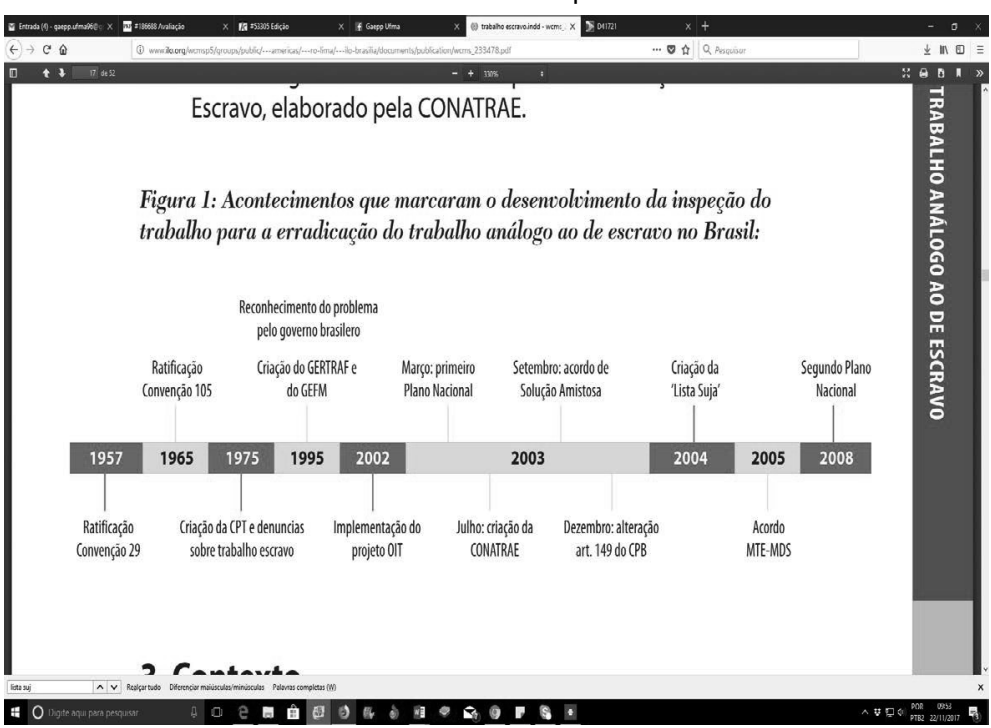

Fonte: ORGANIZAÇÃO INTERNACIONAL DO TRABALHO. As boas práticas da inspeção do trabaIho no Brasil: a erradicação do trabalho análogo ao de escravo. Brasília, DF, 2010. p. 15. Disponível em:<http://www.lo.org/wcmsp5/groups/public/---americas/---ro-lima/---ilo-brasilia/documents/publication/wcms_233478.pdf>. Acesso em: 30 nov. 2016.

Ocorre que, embora tenham sido implementadas políticas públicas em parceria com a Organização Internacional do Trabalho, consoante a revisão bibliográfica realizada, é possível verificar que algumas legislações trabalhistas ainda estão sendo descumpridas, sobretudo no que diz respeito à mão de obra escrava, visto que entre os anos de 2003 e 2013, 10.709 (dez mil setecentos e nove) trabalhadores, em situação análoga à escravidão, foram resgatados por fiscais do governo.

Desses números, de acordo com Barros e outros (2014, p. 6), foram resgatados pelo Ministério do Trabalho e Emprego (MTE), 39 operadores de colhedoras e motoristas de tratores e caminhões, que chegaram a cumprir jornadas de 27 horas seguidas, "[...] o caso é uma prova de que a mecanização, defendida como saída para a escravidão nos canaviais, não garante necessariamente trabalho decente no campo [...]". 
Já em 2013,

[...] a Justiça Federal condenou o responsável pelo Engenho do Poço, no município de Palmares (PE), a 13 anos e seis meses de reclusão por submeter 62 cortadores de cana à condição análoga à de escravo; dois deles eram adolescentes. Durante o trabalho, eles não contavam com equipamentos de proteção, não recebiam alimentação adequada e sequer tinham acesso à água potável. (BARROS et al., 2014, p. 6).

Isso significa que é, além de uma infração trabalhista, como visto anteriormente, um crime, como determina o artigo $149^{\circ}$ do Código Penal, na redação dada pela Lei $\mathrm{n}^{\circ} 10.803$, de 11 de dezembro de 2003: "[...] reduzir alguém à condição análoga à de escravo, quer submetendo-o a trabalhos forçados ou a jornada exaustiva, quer sujeitando-o a condições degradantes de trabalho, quer restringindo, por qualquer meio, sua locomoção em razão de dívida contraída com o empregador ou preposto [...]”. (BRASIL, 2003).

Complementando esse dispositivo, o art. $203^{\circ}$ do Código Penal também prevê pena de detenção de um a dois anos e multa, além da pena correspondente à violência, para quem "[...] frustrar, mediante fraude ou violência, direito assegurado pela legislação do trabalho". O mencionado artigo procura punir a prática de servidão por dívida, quando estabelece que a mesma pena seja aplicada a quem "[...] obriga ou coage alguém a usar mercadorias de determinado estabelecimento, para impossibilitar o desligamento do serviço em virtude da dívida"; "[...] impede alguém de se desligar de serviços de qualquer natureza, mediante coação ou por meio de retenção de seus documentos pessoais ou contratuais." (BRASIL, 2003).

Ademais, o Código Penal também prevê em seu artigo $132^{\circ}$, pena de três meses a um ano de prisão para quem expõe a vida ou a saúde de outrem a perigo direto ou iminente, e, em seu artigo $197^{\circ}$, condena o constrangimento ilegal que impede a liberdade dos trabalhadores.

Outros dispositivos importantes são os artigos $206^{\circ}$ e o artigo $207^{\circ}$, que punem, respectivamente, o aliciamento para fins de emigração e migração e o recrutamento do trabalhador fora do local de execução do trabalho mediante fraude ou cobrança de qualquer quantia do trabalhador ou quando não é assegurado o retorno do trabalhador ao local de recrutamento. 
No entanto, a escravidão moderna pode ser caracterizada por: jornada exaustiva, no que concerne ao expediente penoso que vai além de horas extras e coloca em risco a integridade física do trabalhador, porque o tempo de descanso não é suficiente para que ele consiga recuperar as forças para a próxima jornada; trabalho forçado, que trata de ameaças e violência física ou psicológica; condições degradantes, que vão dos alojamentos precários à falta de equipamentos de proteção e alimentação insalubre e servidão por dívida, que diz respeito a dívidas ilegais referentes a gastos com transporte, alimentos e ferramentas para prender o trabalhador ao local de trabalho. (BARROS et al., 2014).

\section{CONDIÇÕES DE VIDA DO TRABALHADOR CANAVIEIRO}

Diante do apresentado, resta analisar qual o perfil dos trabalhadores canavieiros, e em que condições eles vivem. Pode-se concluir que são migrantes e de baixa escolaridade e, em geral, sua participação no corte da cana-de-açúcar no setor é sazonal, deixando suas cidades de origem apenas durante o período da colheita. (BARROS et al., 2014).

Na sua atividade laboral diária, um trabalhador pode chegar a cortar até 12 (doze) toneladas de cana, por dia, caminhar até $8,8 \mathrm{~km}$, desferir cerca de 133.332 golpes de facão, fazer 36.630 flexões e giros com o corpo e perder até 8 litros de água. (ALVES, 2006).

Por conseguinte, As boas práticas da inspeção do trabalho no Brasil, dadas pela OIT (2010), determinam que podem caracterizar condições degradantes: o alojamento; a susceptibilidade de doenças; as condições de saneamento básico; a alimentação; a remuneração inadequada e salários atrasados, maus tratos e violência.

Sendo assim, o estudo, quando se refere ao alojamento, afirma que "[...] os trabalhadores são comumente alojados em barracas precárias de lona ou de folhas de palmeiras no meio da mata, expostos a uma série de riscos." e à susceptibilidade de doenças, "[...] há um alto índice de doenças tropicais, como a malária e a febre amarela, além de elevada incidência de outras doenças menos comuns em outras regiões, como a tuberculose." (ORGANIZAÇÃO INTERNACIONAL DO TRABALHO, 2010, p. 16-17). 
No que diz respeito ao saneamento básico, os itens se confundem, pois o trabalhador pode ter suas necessidades básicas desrespeitadas, vindo a sofrer com a falta de água potável, e alimentação adequada, assim como banheiro apropriado, além de serem comuns os maus tratos e a violência, afetando a sua saúde e sua dignidade.

As condições de vida dessa classe trabalhadora é tão degradante, que na maioria das vezes, quando falece um trabalhador, a causa mortis no atestado de óbito é vaga. Porém há relatos de amigos e familiares, informando que antes de morrerem, os trabalhadores haviam reclamado de excesso de trabalho, dores no corpo, câimbras, falta de ar, desmaios. (ALVES, 2006).

\section{CONCLUSÃO}

As legislações que regem o setor canavieiro no Brasil possuem uma ampla abrangência das diferentes problemáticas relacionadas às condições de trabalho dos cortadores de cana, como a permanência do trabalho escravo, o desamparo dos trabalhadores sem serviços de saúde, educação, em precárias condições de higiene, a falta de apoio dos sindicatos e ausência de salários fixos. Porém muitos desses problemas ainda continuam fazendo parte do dia a dia do cortador de cana, relacionados principalmente ao trabalho escravo (SANTOS, 2015) e o salário por produção (GUANAIS, 2012) devido ao descumprimento das leis por parte dos empregadores, o que requer uma maior fiscalização por parte do governo.

Embora a situação dos outros contratos de trabalho possa ser afetada pelas recentes reformas trabalhistas que resguardam principalmente os direitos do empregador, invertendo a ordem do princípio da hipossuficiência no Direito do trabalho, a situação do trabalhador canavieiro não se verá necessariamente alterada, considerando que as condições laborais destes são, em muitos casos. análogas à escravidão.

Desse modo, o principal causador das precárias condições de trabalho nas quais estão imersos os cortadores de cana de açúcar é a forma de pagamento estabelecida pelos empregadores do setor, baseado na produção do cortador e não num salário fixo; esse fato faz com que o cortador, com o objetivo de cortar mais quantidade de cana para ter uma maior ganância, trabalhe por jornadas mais longas, sem os intervalos correspondentes e com um maior esforço de trabalho. (ALVES, 2006). Por essa razão, enquanto não for ado- 
tada pelos empregadores, uma forma de pagamento por salário fixo e acorde com as necessidades dos trabalhadores, a qualidade de vida continuará afetada por recorrentes problemas de saúde.

A substituição total do trabalho manual para dar passo à coleta mecânica é uma opção que permitiria eliminar as consequências da força de trabalho dos cortadores de cana, porém é preciso uma alternativa de trabalho como a proposta feita por Alves (2006), de usar as terras liberadas pela mecanização em programas públicos de reforma agrária para que os ex-cortadores de cana produzam alimentos destinados à segurança alimentar local e regional.

Assim, considerando as legislações vigentes e os dados apresentados, embora o trabalhador canavieiro possua direitos previstos em Convenções Internacionais, na CF e na legislação infraconstitucional, é possível perceber que ainda há muitos casos de trabalhos forçados, não podendo considerar, portanto, que as leis estudadas estão contribuindo para melhoria da qualidade de vida dos trabalhadores que atuam no setor sucroalcooleiro.

\section{REFERÊNCIAS}

ALVES, F. Por que morrem os cortadores de cana? Saúde e Sociedade, São Paulo, v. 15, n. 3, p. 90-98, set./dez. 2006.

. Processo de trabalho e danos à saúde dos cortadores de cana. InterfacEHS: Revista de Gestão Integrada em Saúde do Trabalho e Meio Ambiente, São Paulo, v. 3, n. 2, p. 1-26, 2008.

ARIED JUNIOR, V. R. Avaliação da Sustentabilidade de um Sistema de Produção da Cana-de-Açúcar Orgânica. 2013. 223 f. Dissertação (Mestrado) - Universidade Federal de São Carlos, São Carlos, SP, 2013.

BARROS, C. J. et al. As condições de trabalho no setor sucroalcooleiro. São Paulo: Escravo nem Pensar, 2014. Folder. Disponível em: <http://reporterbrasil.org.br/wp-content/ uploads/2015/02/26.-Folder_Sucroalcooleiro_web_baixa.pdf $>$. Acesso em: 27 nov. 2016.

BIODIVERSIDAD EN AMÉRICA LATINA Y EL CARIBE. Brasil: como não cair na cana. [S.1.], 2006. Disponível em: $<$ http://www. biodiversidadla.org/content/view/full/26140>. Acesso em: 10 out. 2016. 
BRASIL. Constituição. Constituição da República Federativa do Brasil de 1988. Brasília, DF, 1998. Disponível em:<http://www. planalto.gov.br/ccivil_03/Constituicao/Constituicao.htm $>$. Acesso em: 27 nov. 2016.

. Presidência da República. Lei no 5.889 , de 8 de junho de 1973. Estatui Normas Reguladoras do Trabalho Rural. Diário Oficial da União, Brasília, DF, 11 jun. 1973. Disponível em:<http://www. planalto.gov.br/ccivil_03/leis/L5889.htm> Acesso em: 27 nov. 2016.

. Lei $\mathrm{n}^{\mathrm{o}} 10.803$, de 11 de dezembro de 2003. Altera o $\overline{\text { art. } 149}$ do Decreto-Lei $n^{\circ} 2.848$, de 7 de dezembro de 1940 - Código Penal, para estabelecer penas ao crime nele tipificado e indicar as hipóteses em que se configura condição análoga à de escravo. Diário Oficial da União, Brasília, DF, 12 dez. 2003. Disponível em: $<>$. Acesso em: 16 out. 2017.

Lei ${ }^{\circ} 11.718$ de 20 de junho de 2008. Acrescenta artigo à Lei ${ }^{\circ} 5.889$, de 8 de junho de 1973, criando o contrato de trabalhador rural por pequeno prazo; estabelece normas transitórias sobre a aposentadoria do trabalhador rural; prorroga o prazo de contratação de financiamentos rurais de que trata o $\S 6^{\circ}$ do art. $1^{\circ}$ da Lei $\mathrm{n}^{\mathrm{o}} 11.524$, de 24 de setembro de 2007; e altera as Leis $\mathrm{n}^{\circ} \mathrm{s} 8.171$, de 17 de janeiro de 1991, 7.102, de 20 de junho de 1993, 9.017, de 30 de março de 1995, e 8.212 e 8.213 , ambas de 24 de julho de 1991. Diário Oficial da União, Brasília, DF, 23 jun. 2008. Disponível em:<http://www2.camara.leg.br/legin/fed/lei/2008/lei-11718-20junho-2008-576871-normaatualizada-pl.html $>$ Acesso em: 27 nov. 2016.

. Senado Federal. Secretaria-Geral da Mesa. Secretaria de Informação Legislativa. Lei ${ }^{\circ} 13.467$, de 13 de julho de 2017. Altera a Consolidação das Leis do Trabalho (CLT), aprovada pelo DecretoLei $\mathrm{n}^{\circ} 5.452$, de $1^{\circ}$ de maio de 1943 , e as Leis $n^{\text {os }} 6.019$, de 3 de janeiro de 1974, 8.036, de 11 de maio de 1990, e 8.212, de 24 de julho de 1991, a fim de adequar a legislação às novas relações de trabalho. Diário Oficial da União, Brasília, DF, 14 jul. 2017. Disponível em:<http://www.planalto.gov.br/ccivil_03/_ato2015-2018/2017/lei/ L13467.htm>. Acesso em: 16 out. $201 \overline{7}$.

. Supremo Tribunal Federal. Mandado de Segurança (MS) 22164-0 São Paulo, 30 de outubro de 1995. Diário da Justiça Eletrônico, Brasília, DF, emen. v. 01809-0, p. 1155-1190, 17 nov. 1995. Relator Ministro Celso de Mello. Disponível em: $<$ http://www. 
TRABALHADOR CANAVIEIRO NO BRASIL: estudo da legislação sobre contratação e condições de trabalho

stf.jus.br/portal/constituicao/artigobd.asp?item $=\% 202004>$ Acesso em 30 de nov. de 2016.

CAMARGO, A. L. O trabalhador canavieiro e suas relações de trabalho. [S. 1.], 2009. Disponível em: $<$ http://www.egov.ufsc.br/portal/ conteudo/o-trabalhador-canavieiro-e-suas-rela $\% \mathrm{C} 3 \% \mathrm{~A} 7 \% \mathrm{C} 3 \% \mathrm{~B} 5$ esde-trabalho> Acesso em: 27 de nov. de 2016.

FEDERAÇÃO DOS TRABALHADORES NA AGRICULTURA DO ESTADO DE GOIÁS. Convenção de Trabalho do Setor Sucroalcooleiro Goiano 2015/2016. Gioânia: Gráfica Liberdade, 2015. Disponível em:<http://www.fetaeg.org.br/NetManager/documentos/ convencao_coletiva_do_trabalho_do_setor_sucroalcooleiro_goiano. pdf $>$ Acesso em:26 nov. 2016.

FEDERAÇÃO DOS TRABALHADORES NA AGRICULTURA DO ESTADO DO PERNAMBUCO. Convenção Coletiva de Trabalho 2014/2015. Recife, 2014. Disponível em:<http://www.fetape.org. br/imagens/documentos/Convencao_Coletiva_de_Trabalho_dos_ Canavieiros_2014.2015.pdf>. Acesso em: 26 nov. 2016.

GONÇALVES, D. B. A regulamentação das queimas e as mudanças nos canaviais paulistas. 2002. 113 f. Dissertação (Mestrado em Desenvolvimento Econômico, Espaço e Meio-Ambiente) - Instituto de Economia, Universidade de São Carlos, São Carlos, SP, 2002.

Mar de cana, deserto verde?: dilemas do desenvolvimento sustentável na produção canavieira paulista. 2005. $256 \mathrm{f}$. Tese (Doutorado em Engenharia de Produção) - Programa de PósGraduação em Engenharia de Produção, Universidade Federal de São Carlos, São Carlos, 2005.

GUANAIS, J. B. O salário por produção enquanto a uma estratégia empresarial: estímulo à intensificação do trabalho dos cortadores de cana Brasileiros. International Journal on Working Conditions, Porto, n. 3, p. 65-84, 2012.

MORAES, M. A. O mercado de trabalho da agroindústria canavieira: desafios e oportunidades. Economia Aplicada, Riberião Preto, v. 11, n. 4, p. 605-619, out./dez. 2007.

ORGANIZAÇÃO INTERNACIONAL DO TRABALHO. As boas práticas da inspeção do trabalho no Brasil: a erradicação do trabalho análogo ao de escravo. Brasília, DF, 2010. Disponível em:<http:// www.ilo.org/wcmsp5/groups/public/---americas/---ro-lima/---ilobrasilia/documents/publication/wcms_233478.pdf>. Acesso em: 30 nov. 2016. 
Convenção n ${ }^{\circ}$ 29, 28 de junho de 1930. Trabalho forçado ou obrigatório. Genebra, 1930. Disponível em: $<$ http://www.oitbrasil.org. br/node/449>. Acesso em: 30 nov. 2016.

Declaração sobre os princípios e direitos fundamentais do trabalho. Genebra, 1998. Disponível em:<http://www.oitbrasil. org.br/content/declara\%C3\%A7\%C3\%A3o-da-oit-sobre-osprinc $\% \mathrm{C} 3 \% \mathrm{AD}$ pios-e-direitos-fundamentais-no-trabalho-e-seuseguimento>. Acesso em: 27 nov. 2016.

PAES, L. A. D. Emissões nas queimadas de cana, controle. In: MACEDO, I. C. (Org). A energia da cana-de-açúcar: doze estudos sobre a agroindústria da cana-de-açucar no Brasil e sua sustentabilidade. 2. ed. São Paulo: Berlendis \& Vertecchia: UNICA, 2007. p. 85-89.

PARANAIBA, A.; FERREIRA, G. L. A Expansão Canavieira e os Efeitos Sociais em Goiás. Boletim de Conjuntura Econômica e do Mercado de Trabalho do Estado de Goiás, Goiânia, v. 2, p. 37-48, jun. 2013.

PIRES, R. A. P; FERREIRA, O. M. Utilização da vinhaça na bio-fertilização da cultura da cana-de-açúcar: estudo de caso em Goiás. Goiânia: Universidade Católica de Goiás, 2008.

RODRIGUES, D.; ORTIZ, L. Em direção á sustentabilidade da produção de etanol de cana de açúcar no Brasil: Amigos da terra Brasil. Porto Alegre: Amigos da Terra; São Paulo: Vittae Civilis, out. 2006.

SANTOS, A. M. F. T. Cana doce, trabalho amargo: o trabalho escravo na expansão territorial do agronegócio sucroenergético no estado de Goiás. 2015. 270 f. Dissertação (Mestrado em Geografia) Universidade Federal de Goiás, Goiânia, 2015.

SPECIAN, V.; FIGUEIREDO, M. A. G. O Sucroalcooleiro e os Indicadores da Rede de Agricultura Sustentável para o Trabalho no Corte da Cana: uma possibilidade de aplicação. In: ENCONTRO NACIONAL DA ANPPAS, 5., Florianópolis, 2010. Anais... Florianópolis: ANPPAS, 2010. Disponível em: $<$ http://www.anppas. org.br/encontro5/cd/artigos/GT2-186-173-20100809151236.pdf $>$. Acesso em: 1 dez. 2016. 